\title{
Choosing the Impregnants by Thermogravimetric Analysis for Preparing Rayon-Based Carbon Fibers
}

\author{
Fanlong Zeng ${ }^{1,4}$ Ding Pan $^{1,2}$ and Ning $\operatorname{Pan}^{2,3}$
}

\begin{abstract}
The pyrolytic process in preparing rayon into activated carbon fiber was studied by thermogravimetric analyses (TGA) and differential thermal gravimetry (DTG). For the promotion of the pyrolytic reaction and increment of carbonization yield, impregnants including phosphoric acid (PA) and its three ammonium salts, as well as the ammonium sulfate (AS), are added respectively for best resultant both air and nitrogen atmospheric environments. The TGA and DTG curves for different cases - various combinations of impregnants and environment - are examined and some features from the curves are selected to characterize each curve more efficiently. The influence of the impregnants as well as the atmospheric conditions are investigated and some useful conclusions are drawn, which are deemed critical in quality control of the resultant activated carbon fibers.
\end{abstract}

KEY WORDS: Activated carbon fiber; rayon; impregnants; thermogravimetric analysis; differential thermal gravimetry; specific surface area.

\section{INTRODUCTION}

Activated carbon fiber (ACF) has been extensively studied and produced on a commercial scale for several decades since it first appeared in the 1960s. Owing to its special porous structure and associated excellent absorption and desorption properties, ACF has attained considerable importance in many high technological areas [1-2]. Yet its wider applications are still limited by their high cost. Rayon fiber is currently a major raw material for producing $\mathrm{ACF}$ in industry since manufacturing processes are both simple and easily controllable.

\footnotetext{
${ }^{1}$ Carbon Fiber Division of the College of Materials, State Key Laboratory for the Modification of Chemical Fiber and Polymer Materials, Dong Hua University, Shanghai, 200051, PR China.

2 Center of Soft Fibrous Matters, Dong Hua University, Shanghai, 200051, PR China.

${ }^{3}$ Division of Textiles and Clothing, Biological and Agricultural Engineering Department, University of California, CA, 95616, USA.

${ }^{4}$ To whom correspondence should be addreseed.

E-mail: zfl@dhu.edu.cn
}

The commonly used processing technologies in ACF production from rayon generally consist of four steps: impregnation of the rayon with chemicals; oxidation in air at lower temperature $\left(<300^{\circ} \mathrm{C}\right)$; carbonization under the protection of nitrogen at $300-900^{\circ} \mathrm{C}$; and finally activation with water steam or carbon dioxide at $700-1200^{\circ} \mathrm{C}$ [3-4]. In other words, the cellulosic macromolecules of rayon are translated into carbon by impregnation, oxidation, pyrolysis or carbonization successively so that numerous pores are formed on the surface of carbon (fiber) by activation. For the final product, the yield of carbon in theory is $44.5 \%$. However, in reality fierce thermal decomposition of rayon produces other volatile substances such as carbon dioxide, aldehydes, organic acids and tars [5-6], which greatly reduce the yield. Nevertheless, a pyrolytic mechanism can be significantly moderated by adding proper chemicals (impregnants or flame retardants) [6-7] so as to reduce the burning loss thereby improving the yield and properties of the products and achieving higher efficiency and lower cost [8-10]. Therefore, selection of suitable impregnants material for this purpose is essential for the entire process. 
Many studies in rayon-carbon fiber conversion have been conducted [11-12]. Yet, there have been relatively few reports on the effect of the impregnants on conversion yield. There are many chemicals that may be used as impregnants for rayon-based activated carbon fiber (RACF), and manufacturers select the impregnants based solely on empirical observation; in fact, nearly all select Lewis acids, which can also serve as flame retardants for cellulosic materials and have hence been studied widely for many years for that purpose[13]. But strong acidic retardants could easily result in the formation of levoglucosan, a carbon-containing volatile substance [6], thus lowering the carbon yields for manufacturing RACF.

In general inorganic phosphates and sulfates with nitrogen have better flame retardant effects; however, which ones work better for ACF during heat treatment from $150^{\circ} \mathrm{C}$ to $800-1000^{\circ} \mathrm{C}$ have not been reported systematically.

Among the impregnants or burning retardants for RACF process, phosphate and ammonium salts are often used $[2,8]$, particularly dibasic ammonium phosphate (DAP) $\left[\left(\mathrm{NH}_{4}\right)_{2} \mathrm{HPO}_{4}\right]$ and ammonium dihydrogen phosphate (ADP) $\left[\mathrm{NH}_{4} \mathrm{H}_{2} \mathrm{PO}_{4}\right]$. Nevertheless, it is not clear $(a)$ why these two salts are more favored over other compounds, $(b)$ how these salts affect the yields and the specific surface areas of ACF produced, and finally $(c)$ which one of the two types performs better? These are the major issues in the present work. More specifically, we will examine the effects of impregnants such as DAP, ADP, ammonium phosphate (AP) $\left[\left(\mathrm{NH}_{4}\right)_{3} \mathrm{PO}_{4}\right]$, phosphoric acid (PA) $\left[\mathrm{H}_{3} \mathrm{PO}_{4}\right]$ and ammonium sulfate (AS) $\left[\left(\mathrm{NH}_{4}\right)_{2} \mathrm{SO}_{4}\right]$ in air and nitrogen environments.

Previously, the differential thermal analysis (DTA) and differential scanning calorimetry (DSC) have been used to investigate the thermal behaviors of flame retardants [14]. Thermogravimetric analysis (TGA) and differential thermal gravimetry (DTG) were also used to provide clues to cellulose pyrolysis $[3,15-16]$. Nevertheless, there is still no clear relationship between the features on the DSC or DTG curves and the carbon yield for ACF. Actually, when tested by TGA, the heat treatment of rayon for ACF at lower temperatures $\left(<300^{\circ} \mathrm{C}\right)$ in air is very similar to the decomposing process in air of an organic polymer. Moreover, the TGA can determine the ACF yield rapidly for different samples. Therefore, by analyzing the effect of phosphoric acid and the aforementioned ammonium salts, we hope to establish a relationship between the impregnants and the yields and quality of ACF that will be helpful in ACF quality control and, hopefully, in finding new and more efficient impregnants.

\section{EXPERIMENTAL}

\subsection{Preparation of Samples}

Non-woven felt strips of rayon were collected as the raw material and were cleaned with water, dried, and soaked for $3 \mathrm{~h}$ in baths of different impregnant solutions with the same concentration; i.e. $3.5 \mathrm{wt} \%$. The entire process follows the widely adopted route in fireproof treatments where cellulosic fabrics are pre-treated with retardants and the amount of retardant absorbed ranges generally from 5 to $20 \%$ $[9,13]$ based on the weight of fabric. The processes of the burning retardant finish generally consist of the following procedures: the impregnants are first dissolved in water; next the rayon specimens are impregnated in the solutions, pressed and dried at $100-120^{\circ} \mathrm{C}$; then curing occurs in an oven at 150 $190^{\circ} \mathrm{C}$ for 5-30 min. The retardants or impregnants generally used include inorganic and organic chemicals such as DAP, ADP, borax, THPC $\left[\mathrm{P}\left(\mathrm{CH}_{2} \mathrm{OH}\right)_{4} \mathrm{Cl}\right]$, APO $\left[\left(\left(\mathrm{CH}_{2}\right)_{2} \mathrm{~N}\right)_{2} \mathrm{PO}\right]$, Pyrovatex $\mathrm{CP}$ (Ciba-Geigy Ltd.), Cyagard RF-1 (Cyanamide Ltd.), etc. A larger amount of impregnants slows down the pyrolysis and hence increases the carbon yield. To ascertain the sensitivity of the relationship between the amounts of different impregnants and yield, a lower concentration was preferred.

The bath ratio is $1: 40 \mathrm{w} / \mathrm{w}$ (rayon weight/solution weight, which is a common ratio used in industry) [9, 13]. The rayon strips were drawn, pressed to remove excessive solution, dried at $120^{\circ} \mathrm{C}$, and finally cut into small samples for TGA.

\subsection{Preparation of ACF}

The pre-treated rayon strips were put into an oven in air and held for $30 \mathrm{~min}$ at each of the following temperature stages: $175^{\circ} \mathrm{C}, 205^{\circ} \mathrm{C}$ and $245^{\circ} \mathrm{C}$. The strips were removed from the oven at the end of each temperature stage while the oven was heated to the next temperature. Afterwards, the strips were placed into a tubular stove with slit-ends for carbonization in nitrogen. Again they were kept for $30 \mathrm{~min}$ at each of the following temperatures: $350^{\circ} \mathrm{C}$, $550^{\circ} \mathrm{C}$ and $850^{\circ} \mathrm{C}$. The strips remained in the stove during the temperature elevation (heating rate, $30^{\circ} \mathrm{C} /$ min). The ACFs were made after the strips were 
finally treated in the stove with water (steam) at $900^{\circ} \mathrm{C}$ for $20 \mathrm{~min}$.

\subsection{TGA analysis}

The TGA analysis takes place during the oxidation and carbonization using a TMA-7 system (PerkinElmer Ltd., USA) at a heating rate of $20^{\circ} \mathrm{C} / \mathrm{min}$.

\subsection{Yields Analysis}

Yield is defined as the ratio of the weight of the strips after thermal treatment (carbonization and activation) and before pre-treatment in the impregnant solutions. Since the rayon specimen and absorbed impregnants will gradually decompose and generate some volatile substances that escape during heating, the ratio (yield) should be less than $100 \%$ except at low temperatures where the remaining impregnants make it possible for the yield (by definition) to exceed $100 \%$. To eliminate this case, the treatment temperature should exceed $600^{\circ} \mathrm{C}$ for more than $0.5 \mathrm{~h}$ so the impregnants can be completely burned away [8, 17] and true yields are obtained.

\subsection{Specific Surface Area Measurements $\left(S_{\text {BET }}, \mathrm{m}^{2} / \mathrm{g}\right)$}

The specific surface areas of the ACFs were measured using the BET method (e.g., physical absorption of nitrogen at $-196^{\circ} \mathrm{C}$ according to the GB2596-81 test; National Standard in China).

\section{RESULTS AND DISCUSSION}

Generally, fast pyrolysis is non-beneficial to the formation of solid (textured or aromatic) carbon from rayon or poly(acrylonitrile) (PAN) and could accelerate side-reactions to release volatile carbon-containing substances that lead to low yields. TGA is often considered an effective method for determining the thermal stability of organic macromolecules. On the basis of relative decomposition temperatures and the shape of DTG curves, a preliminary evaluation of pyrolytic reactions can be accomplished. Relatively deeper and narrower peaks reflect faster reactions; and, weight losses are likely to be greater so that lower carbon yields result. Conversely, flatter pyrolytic peaks show moderate reactions and consequently result in higher carbon yields. Therefore, the effect of pyrolysis of rayon using different impregnants can be quantified by using TGA, DTG. Thermal decomposition (weight loss) and the rate of weight loss can be used to compare the relative yields of carbonization.

\subsection{Pyrolytic Behaviors of Rayon Treated with DAP and ADP}

Figure 1 represents the TGA and DTG curves in air and nitrogen, respectively, of rayon treated with DAP. The thermal decomposition of rayon takes place between $150^{\circ} \mathrm{C}$ and $250^{\circ} \mathrm{C}$ in both environments, with weight losses in air to $53 \%$ at $250^{\circ} \mathrm{C}$ and $58 \%$ at $300^{\circ} \mathrm{C}$. When the treatment temperature is between $250^{\circ} \mathrm{C}$ and $500^{\circ} \mathrm{C}$, the shape of the curve in the air is similar to that in nitrogen. However, the shapes of two curves near $200^{\circ} \mathrm{C}$ are different. A sharper drop in a nitrogen atmosphere indicates that a more drastic thermal decomposition reaction takes place and that rayon decomposes more rapidly in nitrogen than in the air. The more rapid the pyrolysis, the greater the amount of volatiles generated (i.e. carbon dioxide, aldehydes, organic acids) and the lower the ACF yield. The presence of oxygen (air) is favorable for a higher ACF yield.

On the other hand, rayon is thermally cracked after treatment with ADP in both air and nitrogen (Fig. 2). In contrast to the DAP case (Fig. 1), the shape of the TGA and DTG curves are nearly identical in both environments from $50-500^{\circ} \mathrm{C}$. The presence of oxygen (air) does not noticeably affect the pyrolysis process. The most rapid pyrolytic reaction still occurs near $200^{\circ} \mathrm{C}$ and the weight loss in air is $54 \%$ at $250^{\circ} \mathrm{C}$ and $59.4 \%$ at $300^{\circ} \mathrm{C}$. Relative to the DAP treated material, the ADP pyrolysis peak is somewhat sharper and the yield is lower.

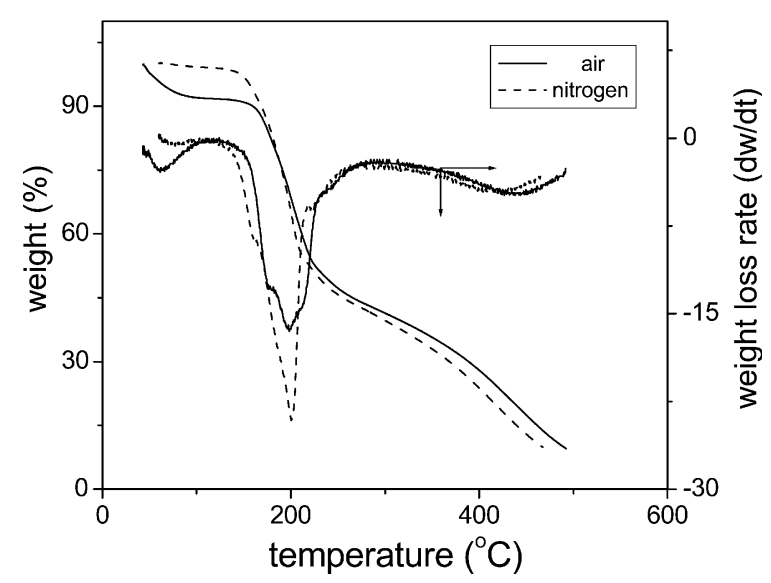

Fig. 1. TGA and DTA curves of rayon treated by dibasic ammonium phosphate (DAP). 


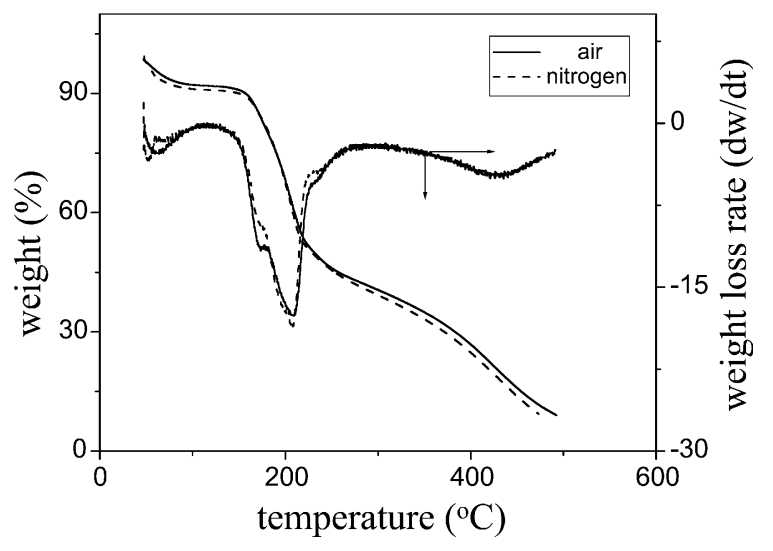

Fig. 2. TGA and DTA curves of rayon treated by ammonium dihydrogen phosphate (ADP).

\subsection{Pyrolytic Behaviors of Rayon Treated with AP and PA}

Pyrolytic degradations of rayon impregnated with AP and PA in air and nitrogen are shown in Figs. 3 and 4, respectively. The major degradations occur between $150-300^{\circ} \mathrm{C}$. The weight losses (in air) at $300^{\circ} \mathrm{C}$ are $64.4 \%(\mathrm{AP})$ and $57.8 \%(\mathrm{PA})$, respectively. In general, the shapes of the pyrolysis peaks are sharper and, in the case of AP, deeper. However, air has not a noticeable affect on peak heights, gradients and positions. The reaction of the APcontaining material overall proceeds more vigorously and with a lower carbon yield, as expected.

\subsection{Pyrolytic Behaviors of Rayon Treated with AS vs. No-impregnants}

When treated with AS, rayon samples exhibit a completely different pyrolytic process compared to

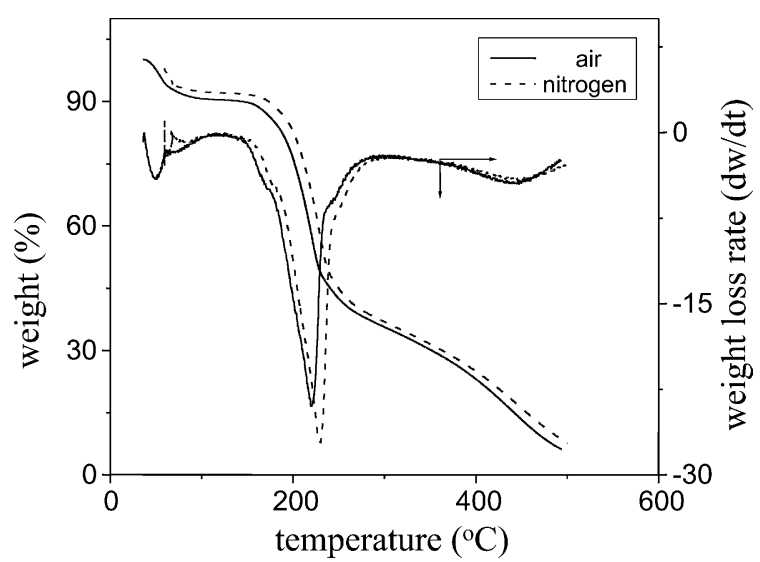

Fig. 3. TGA and DTA curves of rayon treated by ammonium phosphate (AP).

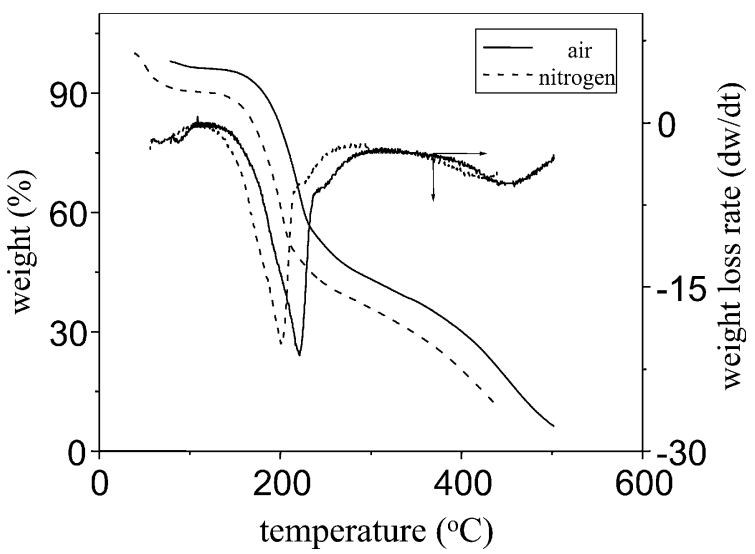

Fig. 4. TGA and DTA curves of rayon treated by phosphoric acid (PA).

DAP, ADP, AP and PA (Fig. 5). Two pyrolytic peaks are observed from $150-300^{\circ} \mathrm{C}$. The maximum weight loss at $300^{\circ} \mathrm{C}$ is $66 \%$. The main peak is both steeper and deeper, and its position is moved to a lower temperature $\left(187^{\circ} \mathrm{C}\right)$. Almost no effect occurs in air on the main peak; however, noticeably there is a reduction in the subsidiary peak at $250^{\circ} \mathrm{C}$. The degradation reaction appears to be fast and leads to lower yields.

Although the maximum cracking temperature (i.e., the position of the main peak on the temperature axis) is about $10-30^{\circ} \mathrm{C}$ lower than those displayed in Figs. 1-4, the yield is less. It seems that the rate of weigh-loss during the pyrolysis, as reflected by the gradient of the peak, correlates more closely to the yield of carbonization than to the pyrolytic temperature.

With no impregnation, a very high temperature must be supplied to overcome the activation energies

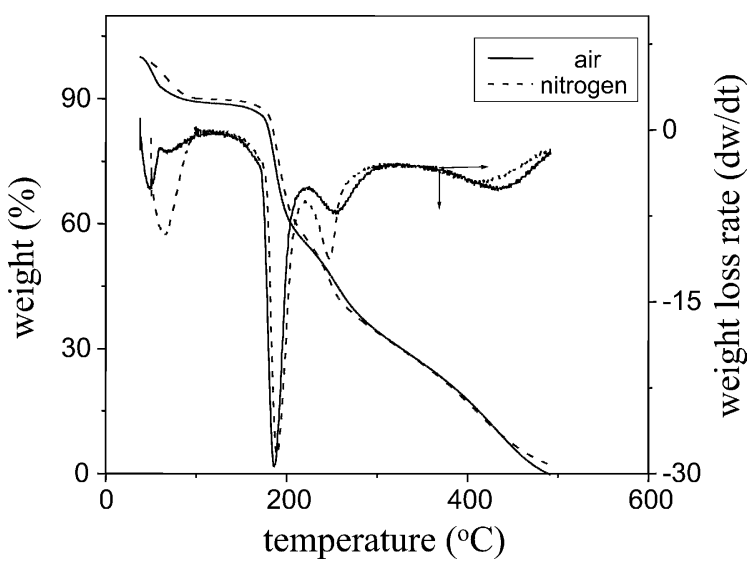

Fig. 5. TGA and DTA curves of rayon treated by ammonium sulfate (AS). 


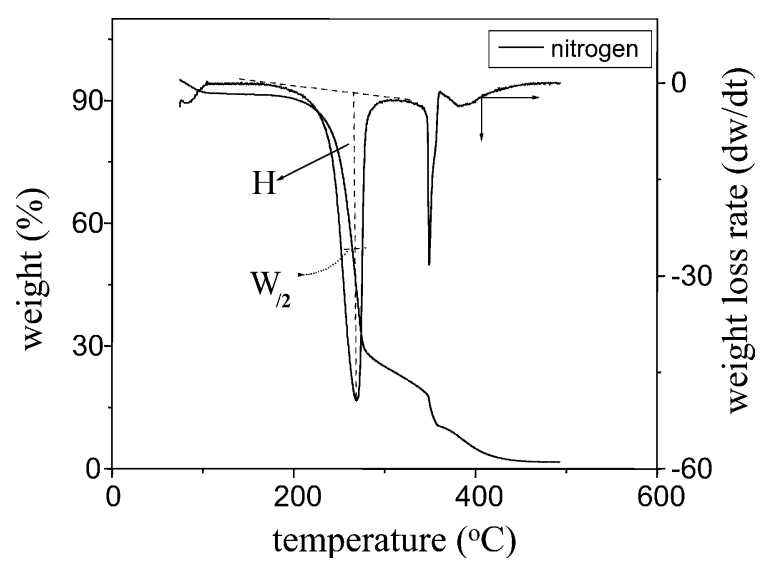

Fig. 6. TGA and DTA curves of rayon with no impregnants treatment.

of the reaction to break the $\mathrm{C}-\mathrm{OH}, \mathrm{C}-\mathrm{H}$ and $\mathrm{C}-\mathrm{O}-\mathrm{C}$ bonds in the cellulosic molecules for the pyrolysis of rayon. Once the critical temperature is attained, the pyrolytic cracking reactions occur, but in a more vigorous manner. Under severe conditions, a large amount of pyrolysates is formed causing an extremely low yield. Figure 6 (solid line) illustrates such a case in which drastic reactions take place at high temperature. The curves in air and in nitrogen are basically identical, as reported previously [18-19]. Moreover, a second peak appears at $349^{\circ} \mathrm{C}$, and a maximum cracking temperature occurs as high as $272^{\circ} \mathrm{C}$. The peak height is 1.7 to 3 times as much as those in Figs. $1-5$, indicating that the cracking reaction is extremely intense. When the rayon sample is heated to $400^{\circ} \mathrm{C}$, the weight loss is almost complete (ca. 95\%), as expected. In general, the impregnants decrease the pyrolytic temperatures and lead to flatter, smaller and sometimes multiple cracking peaks; i.e., they moderate the degradation reactions and increase the yields of carbonization.

\subsection{Analysis of DTG Curves and Predicted Yields}

The shapes of cracking peaks can be characterized by the ratio of the peak height to the peak halfheight width $\left(\frac{H}{W / 2}\right)$. The definition of $\mathrm{H}$ and $\mathrm{W}_{/ 2}$ are shown in Fig. 6 (dash line); the larger value of the ratio, the steeper and thinner the peak. Based on the values of the ratio and the corresponding positions (temperatures) of the main cracking peaks from Figs. 1-6, the yield order can be determined (Table I).

In studies of flame-retardants, it is well known that nitrogen and phosphorus atoms are synergistic $[13,20]$. For example, DAP is a highly effective flame retardant for its $\mathrm{N} / \mathrm{P}$ ratio [21]. There are several reaction mechanisms to explain this phenomenon [13]. For instance, retardants can act by promoting the pyrolysis and carbonization of cellulose. In this case, the impregnants work in a similar manner to a fire retardant and, as a result, DAP affords the highest carbonization yield.

\subsection{Yields of Rayon with Different Impregnants after Oxidation, Carbonization and Activation}

In carbon fiber manufacturing from PAN or rayon, it is difficult for the pyrolytic reactions to be carried out evenly throughout the fiber. It is well known that the heating rate plays a significant role on carbon yields during pyrolysis [9-10]. The yields shown in the TGAs are all extremely low (5-20\%) because of the very high heating rate $\left(20^{\circ} \mathrm{C} / \mathrm{min}\right)$. Temperature elevation in industry is gradual and the process is usually carried out in a step-by-step fashion. Consequently, TGA conditions do not parallel industrial practice. Moreover, residues from impregnants below $500^{\circ} \mathrm{C}$ in the TGA experiment add error to the yield. It has been verified in tests that when the treatment temperatures are above $600^{\circ} \mathrm{C}$ for more than $0.5 \mathrm{~h}$, impregnants are almost completely volatilized $[8,17]$. Hence, the yield results from the above experiments must be corrected.

ACF is prepared according to the procedures described above. The strips are non-woven rayon felt with $50 \times 300 \times 4 \mathrm{~mm}$ (width $\times$ length $\times$ thickness). The experimental conditions and results are summarized in Table II. It can be seen that the lowest yield occurs using PA at $175^{\circ} \mathrm{C}$. This may be a result of the relatively high acidity of the PA solution $(\mathrm{pH}, 4)$, the hydrogen cations of which effect more easily the decomposition and dehydration of the cellulosic chains at lower temperature. When the temperature reaches $245^{\circ} \mathrm{C}$, the yield

Table I. The Ratio of $\frac{H}{W_{/ 2}}$ and Expected Order of Yield

\begin{tabular}{|c|c|c|c|c|c|c|c|c|c|c|c|}
\hline Ratio $\frac{H}{W_{/ 2}}$ & 0.2895 & & 0.3072 & & 0.5295 & & 0.7064 & & 1.5064 & & 1.9812 \\
\hline Order of yield & DAP & $\geq$ & ADP & $>$ & PA & $>$ & AP & $>>$ & AS & $>>$ & No impregnants \\
\hline
\end{tabular}


Table II. Effect of Impregnants on the Yields of Oxidation, Carbonization and Activation of Rayon*

\begin{tabular}{|c|c|c|c|c|c|c|}
\hline \multirow[b]{2}{*}{ Condition/item } & \multicolumn{6}{|c|}{ Impregnants } \\
\hline & $\left(\mathrm{NH}_{4}\right)_{2} \mathrm{H} \mathrm{PO}_{4}(\mathrm{DAP})$ & $\mathrm{NH}_{4} \mathrm{H}_{2} \mathrm{PO}_{4}(\mathrm{ADP})$ & $\left(\mathrm{NH}_{4}\right)_{3} \mathrm{PO}_{4}(\mathrm{AP})$ & $\mathrm{H}_{3} \mathrm{PO}_{4}(\mathrm{PA})$ & $\left(\mathrm{NH}_{4}\right)_{2} \mathrm{SO}_{4}(\mathrm{AS})$ & None \\
\hline $175^{\circ} \mathrm{C}$ oxida. $0.5 \mathrm{~h}, \mathrm{Y}^{1}(\%)$ & 102.01 & 102.64 & 101.4 & 91.03 & 103.7 & 99.48 \\
\hline $205^{\circ} \mathrm{C}$ oxida. $0.5 \mathrm{~h}, \mathrm{Y}(\%)$ & 89.18 & 89.68 & 89.94 & - & 80.99 & - \\
\hline $245^{\circ} \mathrm{C}$ oxida. $0.5 \mathrm{~h}, \mathrm{Y}(\%)$ & 58.94 & 59.49 & 58.79 & 61.39 & 56.54 & 89.70 \\
\hline $350^{\circ} \mathrm{C}$ carb. $0.5 \mathrm{~h}, \mathrm{Y}(\%)$ & 48.45 & 49.92 & 48.38 & 51.82 & 41.72 & 25.82 \\
\hline $550^{\circ} \mathrm{C}$ carb. $0.5 \mathrm{~h}, \mathrm{Y}(\%)$ & 40.65 & 39.77 & 38.99 & 41.22 & 32.42 & 19.81 \\
\hline $850^{\circ} \mathrm{C}$ carb. $0.5 \mathrm{~h}, \mathrm{Y}(\%)$ & 32.99 & 32.66 & 31.87 & 32.03 & 27.33 & 17.25 \\
\hline $900^{\circ} \mathrm{C}$ activ. $20 \mathrm{~min}, \mathrm{Y}(\%)$ & 19.53 & 18.78 & 17.36 & 18.73 & 18.56 & 11.31 \\
\hline $\mathrm{S}_{\mathrm{BET}}^{2}\left(\mathrm{~m}^{2} / \mathrm{g}\right)$ & 1438 & 1289 & 1315 & 1300 & 925 & 885 \\
\hline
\end{tabular}

*Y- yield of rayon after pyrolysis; $S_{\mathrm{BET}^{-}}$specific surface area of activated carbon fiber measured by BET method $\left(\mathrm{N}_{2}\right)$.

spread is less $(56.5-60.4 \%)$ and the rayon samples lose nearly half of their original weight. However, the thermal cracking reaction with no impregnants begins at $245^{\circ} \mathrm{C}$ with a yield of $89.7 \%$. Moreover, the reaction takes place vigorously once the temperature reaches $350^{\circ} \mathrm{C}$, and leads to the largest weight lose (yield, 25.8\%). Phosphoric acid and its ammonium salts as impregnants give good results (yield, $50 \%$ at $350^{\circ} \mathrm{C}$ ), whereas AS gives the poorest results.

If the sample strips are kept at $850^{\circ} \mathrm{C}$ for $30 \mathrm{~min}$, the pyrolysis and carbonization reactions end. Miscellaneous elements (e.g. H, O) other than carbon in the cellulosic molecules are essentially exhausted, as are the impregnants. The effectiveness of various impregnants can hence be evaluated by the yields of the rayon carbonization. The yield data at $850^{\circ} \mathrm{C}$ (Table II) are consistent with the order listed in Table I by TGA.

The RACF data on yields and specific surface areas $\left(S_{\mathrm{BET}}\right)$ are summarized in Table II. DAP gives the highest yield with the largest specific surface area. In practice, yield is often found to be inversely related to the specific surface area. Thus, in both yield and specific surface area DAP is excellent for preparing RACF; ADP and PA are fair, AP is slightly worse, AS is marginal, and no impregnants is the worst.

\section{CONCLUSIONS}

The presence of air (oxygen) is favorable using DAP as an impregnant in rayon to enhance the carbonization yield by pyrolytic decomposition. Little effect is observed with ADP, PA, AP, and AS impregnants. In the formation of ACF from rayon,
DAP is best giving the highest yield and largest specific surface area; ADP and PA are good, AP is fair, and AS is the worst. However, all the impregnated materials increase the ACF yield relative to the absence of an additive.

A peak shape on a DTG curve can be characterized by the ratio of its height to the half-height width $\left(\frac{H}{W_{/ 2}}\right)$. An impregnant that displays a flat TGADTG peak, i.e., a low $\frac{H}{W_{/ 2}}$ ratio, indicates high yields of ACF from rayon and may be used to diagnose effective materials as impregnants.

\section{REFERENCES}

1. N. Worasuwannarak, S. Hatori, H. Nakagawa, and K. Miura, Carbon 41, No. 5, pp. 933.

2. M. Suzuki, Carbon 32, No. 4, pp. 577.

3. F. R. Reinoso, A. C. Pastor, H. Marsh, and M. A. Martinez, Carbon 38, 379.

4. C. Brasquet, B. Rousseau, H. E. Szwarckopf, and P. L. Cloirec, Carbon 38, No. 3, pp. 407.

5. R. F. Schwenker and L. R. Beck, J. Polym. Sci. Part C: $2,331$.

6. F. J. Kilzer and A. Broido, Pyrodynamics 2, 151.

7. C. Morterra and M. J. D. Low, Carbon 23, No. 4, pp. 335.

8. F. He and M. Z. Wang (Ed.), Carbon Fiber and Composite Materials (Chinese) (Scientific Press, Beijing, PRC, (1995) 113-121.

9. Z. Y. Liu and J. T. Zheng, Carbon Techniques (Chinese) 4, 20.

10. J. B. Tomlinson and C. R. Theocharis, Carbon 30, No. 6, pp. 907.

11. R. Fu and L. Liu, Ionic Exchange and Adsorption (Chinese) 14, No. 5, pp. 411.

12. A. Huidobro, A. C. Pastor, and F. R. Reinoso, Carbon 39, 389.

13. M. Lewin and S. B. Sello (Ed.), Handbook of Fiber Science and Technology: Vol. II, Chemical Processing of Fiber and Fabrics, Functional Finishes: Part B: (Marcel Dekker, Inc. New York, (1983) 2-93.

14. A. Bash and M. Lewin, Textile Res. J. 45, No. 3, pp. 246.

15. A. Shindo, Y. Nakanishi, and I. Soma, Appl. Polym. Symp. 9, 271.

16. A. C. Pastor, F. R. Reinoso, H. Marsh, and M. A. Martinez, Carbon 37, No. 8, pp. 1275. 
17. F.L. Zeng and D. Pan, J. Mat. Sci. Eng. (Chinese) 21, No. 5, pp. 651.

18. X. Q. Xu. The Studies of Pre-treatment Technology of Rayonbased Carbon Fiber. The Graduate Thesis of Donghua University (Chinese). (Shanghai, PRC, 1996), pp. 13-14.

19. M. Z. Wang and F. He (Ed.), The Processing, Properties and Application of Carbon Fiber (Chinese) (Scientific Press, Beijing, PRC, (1984) 186-194.
20. J. E. Hendrix, G. L. Drake, and R. H. Barker, J. Appl. Poly. Sci. 16, No. 2, pp. 257-274, 1972.

21. J. Y. Luo and X. M. Luo (Ed.), Flame Retardant Technique of Cellulosic Substrate Materials (Chinese) (Chemical Industry Press, Beijing, PRC, (2003) 39-109. 